\title{
The Effect of BMI and Visceral Fat Percentage on the Development of Bone Metastases in Prostate Cancer
}

\author{
Fusun Aydogan ${ }^{1^{*}}$, Ebuzer Kalender ${ }^{1}$, Murat Rifaioğlu $\mathbf{M}^{2}$, Taner Sümbül $\mathbf{A}^{3}$ and Erhan Yengil ${ }^{4}$ \\ ${ }^{1}$ Department of Nuclear Medicine, Mustafa Kemal University Faculty of Medicine, Hatay/Turkey \\ ${ }^{2}$ Department of Urology, Mustafa Kemal University Faculty of Medicine, Hatay/Turkey \\ ${ }^{3}$ Department of Oncology, Mustafa Kemal University Faculty of Medicine, Hatay/Turkey \\ ${ }^{4}$ Department of Family Medicine, Mustafa Kemal University Faculty of Medicine, Hatay/Turkey
}

*Corresponding author: Fusun Aydogan, Assistant Professor, Department of Nuclear Medicine, Mustafa Kemal University Faculty of Medicine, Hatay/Turkey, Tel: +90 (505) 657 9710; E-mail: drfusunay@yahoo.com

Received date: Jun 05, 2014, Accepted date: Sep 30, 2014, Publication date: Oct 03, 2014

Copyright: (c) 2014 C Aydogan F, et al. This is an open-access article distributed under the terms of the Creative Commons Attribution License, which permits unrestricted use, distribution, and reproduction in any medium, provided the original author and source are credited.

\begin{abstract}
Introduction: Prostate cancer (PCa) second leading cause of cancer-related deaths among men worldwide. There are publications in the literature examining the relation between obesity and $\mathrm{PCa}$, but there is not publication about the relation between obesity and bone metastases in PCa. The aim of this study is to determine whether there is a relation between bone metastasis, PSA, Gleason score, BMI and visceral fat percentage (VFP) in PCa patients.
\end{abstract}

Methods: Thirty-four patients with PCa who performed bone scintigraphy included to study. Mean age was 71.3 \pm 6.9 years. All patients' height, weight, VFP and BMI were calculated. PSA levels, Gleason scores, VFP and BMI of patients with and without bone metastases were compared.

Results: On the bone scintigraphy 14 patients had bone metastasis and there was no metastases in 20 patients. PSA levels and Gleason scores were higher in patients with bone metastases than in patients without bone metastases and this was statistically significant $(p=0.004)$. While the BMI level was $26.15 \mathrm{~kg} / \mathrm{m}^{2}(22.7-33.5)$ in patients with bone metastasis, it was $26.5 \mathrm{~kg} / \mathrm{m}^{2}(20.7-43.9)$ in patients without bone metastasis. VFP was 11 (6-27) in patients with bone metastasis and 9 (3-17) in patients without bone metastasis. Although the VFP was higher in patients with bone metastases; this was not statistically significant $(p=0.15)$.

Conclusion: Our data suggest that there is a significant correlation between bone metastasis and high Gleason score and PSA level, but there is not significant correlation between bone metastasis and BMI, VFP in PCa.

Keywords: Prostate cancer; Bone metastases; Body mass index; Visceral fat percentage

\section{Introduction}

Prostate cancer (PCa) is the second most commonly type of cancer and the second leading cause of cancer-related deaths among men worldwide [1-3]. PCa metastases are seen almost entirely on the bones and they are typically in the osteoblastic forms [4,5]. Bone metastases are commonly detected by bone scintigraphy.

It is widely accepted that obesity increases the risk of several chronic diseases, including type II diabetes, cardiovascular disease, and several types of cancer [6]. The relation between obesity and PCa risk has been studied extensively but remains inconclusive [7]. Several studies reported that higher body mass index (BMI) is related with advanced PCa [8-10]. However we could not find any study in the literature examining the relation between bone metastasis and BMI, visceral fat percentage (VFP) in PCa patients.

The aim of this study is to determine whether there is a correlation between bone metastasis and BMI, visceral fat percentage (VFP), serum total prostate-specific antigen (PSA) level and Gleason score in PCa patients.

\section{Materials and Methods}

Thirty-four patients with PCa who performed bone scintigraphy in our clinic included to study. Mean age was $71.3 \pm 6.9$ years (range 54-85). The patients with renal insufficiency and chronic metabolic disease were excluded from study. Mustafa Kemal University Ethics Committee has approved the study. All patients sent to bone scintigrapy for staging after inital diagnose.

Bone scintigraphy was performed by dual-head gamma cameras (Symbia S, Siemens Healthcare) with low-energy high-resolution parallel-hole collimators. Patients were scanned on anterior and posterior positions. Patients were evaluated with considering their medical histories (trauma, surgery, etc.). The patients with and without bone metastasis were detected on bone scintigraphy. The patients who had metastatic areas less than 3 on scintigraphy, were correlated with other imaging modalities.

All patients' height, weight, body muscle percentage (BMP), body fat percentage (BFP), VFP and BMI were calculated. Measurements were performed by four-terminal hand-foot bioelectrical impedance analyzer (Omron-BF 510).

It was viewed whether there is a relation between the calculated values and Gleason scores, PSA levels and bone metastases. 
Page 2 of 4

\section{Statistical Analysis}

SPSS for Windows 18.0 (Statistical Package for Social Sciences) package programme was used for statistical analysis. Continuous variables were examined with Kolmogorov-Smirnov test in terms of a normal distribution. Relations between nominal variables were examined by the chi-square test and difference of medians between groups were examined by Mann-Whitney $U$ test. Spearman correlation test was used to determine the relations between continuous variables. All statistical datas with $\mathrm{p}<0.05$ were considered as significant.

\section{Results}

On the bone scintigraphy 14 patients had bone metastasis and there was no metastases in 20 patients.

PSA levels were higher in patients with bone metastases than in patients without bone metastases and this was statistically significant $(\mathrm{p}=0.004)$. Also, Gleason scores were higher in patients with bone metastases than in patients without bone metastases and this was statistically significant $(\mathrm{p}=0.001)$ (Figure 1 ).

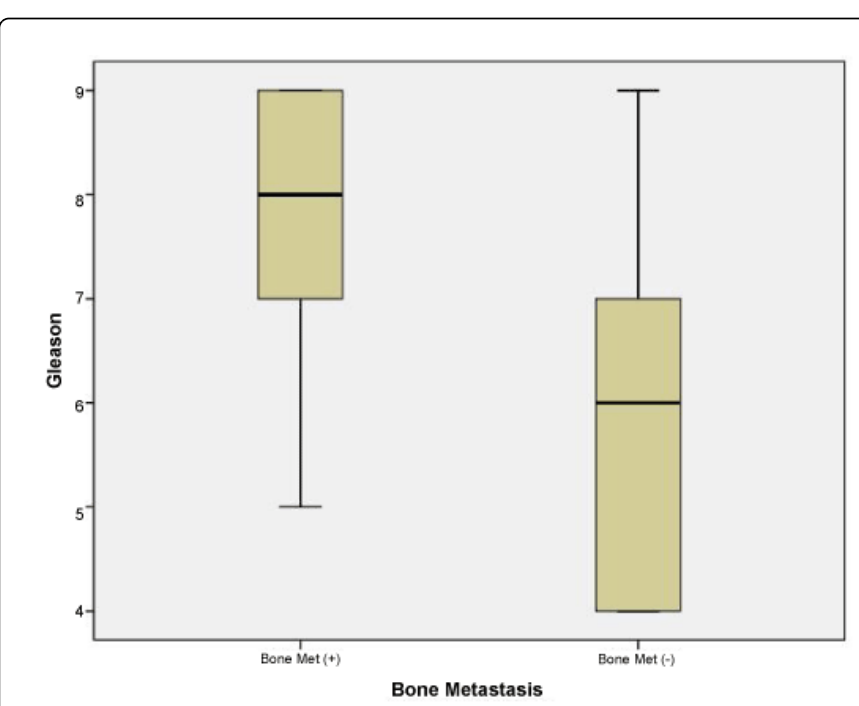

Figure 1: Gleason scores of patients with and without bone metastases.

We found a positive correlation between total PSA level and Gleason score $(\mathrm{p}=0.0001 / \mathrm{rho}=835)$; and BMP, BFP, BMI and age values were similar in groups with and without bone metastasis. BMI, VFP, BMP, BFP, PSA levels and Gleason scores of patients with and without bone metastases were given in Table 1 .

\begin{tabular}{|l|l|l|l|}
\hline & Bone Metastasis $(+)$ & Bone Metastasis $(-)$ & $\mathbf{p}$ \\
\hline Age (year) & $72,50(54-82)$ & $71(61-85)$ & 0.899 \\
\hline PSA (ng/ml) & $100(100-355)$ & $14(13-100)$ & 0.004 \\
\hline Gleason & $8(5-9)$ & $6(4-9)$ & 0.001 \\
\hline BMI $\left(\mathrm{kg} / \mathrm{m}^{2}\right)$ & $26.15(22.7-33.5)$ & $26.5(20.7-43.9)$ & 1 \\
\hline VFP & $11(6-27)$ & $9(3-17)$ & 0.14 \\
\hline
\end{tabular}

\begin{tabular}{|l|l|l|l|}
\hline BMP & $32.8(13.2-45.2)$ & $33.6(24-42)$ & 0.66 \\
\hline BFP & $23(5.8-34.2)$ & $21.7(7.4-47)$ & 0.84 \\
\hline
\end{tabular}

Table 1: BMI, VFP, BMP, BFP, PSA levels and Gleason scores of patients with and without bone metastases.

While the median BMI level was $26.15 \mathrm{~kg} / \mathrm{m}^{2}$ (range 22.7-33.5) in patients with bone metastasis, it was $26.5 \mathrm{~kg} / \mathrm{m}^{2}$ (range 20.7-43.9) in patients without bone metastasis (Figure 2). There was no significant difference between the two groups ( $\mathrm{p}>0.05$ ).

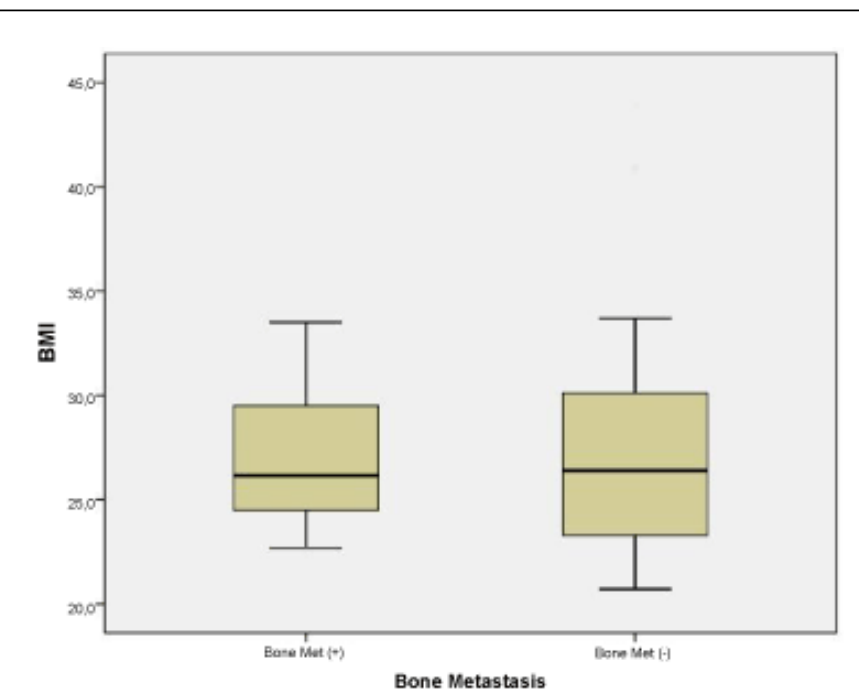

Figure 2: BMI of patients with and without bone metastases.

VFP was 11 (range 6-27) in patients whith bone metastasis and 9 (range 3-17) in patients without bone metastasis. Although the VFP was higher in patients with bone metastases; this was not statistically significant $(\mathrm{p}=0.14)$.

In patients, BMI was positively correlated with VFP and BFP $(\mathrm{p}=0.0001 / \mathrm{rho}=716 ; \mathrm{p}=0.0001 / \mathrm{rho}=0.604)$, and negatively correlated with BMP $(\mathrm{p}=0.029 / \mathrm{rho}=-0.380)$. We found positive correlation between BMI and VFP, BFP; and negative correlation between BMI and BMP.

\section{Discussion}

PCa is recognized as one of the major medical problems facing the male population [11]. Advanced prostate cancer is frequently accompanied by the development of metastasis to bone. Bone is the most frequent site of prostate carcinoma metastasis. Bone metastases identified in up to $90 \%$ of patients dying from prostate carcinoma at autopsy series $[12,13]$.

The sensitivity of bone scintigraphy is $95 \%$ for bone metastases. The most important factor that affecting this sensitivity is tumor type. Bone metastases can be detected easily in PCa as scintigraphically, because the metastases are primarily in osteoblastic form [14].

According to the literature, the increase in serum PSA level is an important indicator for distant organ metastasis in $\mathrm{PCa}$, especially for bone metastasis $[15,16]$. In our study, in accordance with the literature, serum PSA levels in patients with bone metastasis were 
higher than in patients without metastasis and this was statistically significant $(\mathrm{p}<0.05)$.

Yigitbasi et al. and Epstein et al. have reported that the Gleason score is strongly related with patient outcome in PCa patients with bone metastases $[17,18]$. In our study, in accordance with the literature, Gleason scores of patients with bone metastasis were higher than in patients without metastasis and this was statistically significant $(\mathrm{p}<0.05)$.

Obesity is an important problem all over the world and its incidence is increasing day by day. On the worldwide more than half of the adults categorized as being overweight $(\mathrm{BMI} \geq 25)$ and up to $30 \%$ categorized as obese $\left(\mathrm{BMI} \geq 30 \mathrm{~kg} / \mathrm{m}^{2}\right)$ [19]. Obesity is related with a number of chronic diseases such as diabetes, coronary artery disease, hypertension and some cancers [20,21]. In recent years several studies focuse on the relationship between obesity (BMI) and prostate cancer.

The relationship between obesity (BMI) and prostate cancer is variable in epidemiological studies. Positive [10,22], insignificant [23-26] and inverse $[27,28]$ associations were reported between BMI and PCa risk.

Several mechanisms could explain the association of obesity with prostate cancer risk, including the sex steroid hormone, insulin and IGF signaling, and inflammation pathways [7].

Some investigators have reported that higher $\mathrm{BMI}$ is related to increased risk of advanced and higher grade-stage PCa [8-10,21,29]. Rodriguez et al reported that obesity increases risk of prostate cancer mortality [21]. Snowdon et al have suggested that animal product consumption and obesity may be risk factors for fatal prostate cancer [29]. Also several studies showed that BMI is inversely associated with a risk of localized PCa and directly associated with a risk of advanced PCa [7-10,30-32]. Hubbard et al reported that BMI is associated with a $16 \%$ reduced risk of low-grade PCa but a $22 \%$ increased risk of highgrade PCa [32]. Similarly Wright et al reported no association of BMI with low-grade cancer but a positive association with fatal PCa [7]. On the other hand some researchers found inverse association between BMI and PCa risk. Porter and Stanford found that BMI and weight were inversely associated with PCa risk [28].

Beside all of these, we could not reach a publication in the literature examining the relation between BMI and bone metastasis in Pca patients. In our study, there was not significant correlation between bone metastasis and BMI statistically. Also there was no significant correlation between bone metastasis and BMP, BFP.

Although intraabdominal fat makes up only $10 \%$ of total body fat, it is metabolically more active than subcutaneous or peripheral fat [33]. There are a limited number of publications on the literature about the relation between PCa and VFP. In these publications the relation between the presence of cancer and VFP was examined, but the relation between VFP and bone metastasis was not investigated. A study by von Hafe et al showed that PCa patients had a significantly higher abdominal fat area [34]. In our study, we investigated whether there is a correlation between VFP and bone metastases in PCa. Although the VFP was higher in patients with bone metastases; this was not statistically significant $(\mathrm{p}>0.5)$.

\section{Conclusion}

The relation between BMI and PCa is still controversial and there is no consensus on this issue. Positive, inverse and insignificant associations were reported in several studies. The first time in the literature, we investigated the relation between bone metastasis and PSA level, Gleason score, BMI and VFP in PCa. In conclusion our data suggest that there is a significant correlation between bone metastasis and high Gleason score and serum PSA level, but there is no significant correlation between bone metastasis and BMI, VFP in PCa.

\section{References}

1. Siegel R, Naishadham D, Jemal A (2012) Cancer statistics. CA Cancer. J Clin 62: v10-29.

2. Hsing AW1, Tsao L, Devesa SS (2000) International trends and patterns of prostate cancer incidence and mortality. Int J Cancer 85: 60-67.

3. Jemal A, Siegel R, Ward E, Murray T, Xu J, et al. (2007) Cancer statistics. CA Cancer J Clin 57: 43- 66.

4. Lee RJ, Saylor PJ, Smith MR (2011) Treatment and prevention of bone complications from prostate cancer. Bone 48: 88-95.

5. Jin JK, Dayyani F, Gallick GE (2011) Steps in prostate cancer progression that lead to bone metastasis. Int J Cancer 128: 2545-2561.

6. Mokdad AH, Ford ES, Bowman BA, Dietz WH, Vinicor F, et al. (2003) Prevalence of obesity, diabetes, and obesity-related health risk factors, 2001. JAMA 289: 76-79.

7. Wright ME, Chang SC, Schatzkin A, Albanes D, Kipnis V, et al. (2001) Prospective study of adiposity and weight change in relation to prostate cancer incidence and mortality. Cancer. 109: 675-84.

8. Cerhan JR, Torner JC, Lynch CF, Rubenstein LM, Lemke JH, et al. (1997) Association of smoking, body mass, and physical activity with risk of prostate cancer in the Iowa 65+ Rural Health Study (United States). Cancer Causes Control 8: 229-238.

9. MacInnis RJ, English DR, Gertig DM, Hopper JL, Giles GG (2003) Body size and composition and prostate cancer risk. Cancer Epidemiol Biomarkers Prev 12: 1417-1421.

10. Putnam SD, Cerhan JR, Parker AS, Bianchi GD, Wallace RB, et al. (2000) Lifestyle and anthropometric risk factors for prostate cancer in a cohort of Iowa men. Ann Epidemiol 10: 361-369.

11. Heidenreich A, Aus G, Bolla M (2008) EAU guidelines on prostate cancer. European Urol 53: 68-80.

12. Bubendorf L, Schöpfer A, Wagner U, Sauter G, Moch H, et al. (2000) Metastatic patterns of prostate cancer: an autopsy study of 1,589 patients. Hum Pathol 31: 578-583.

13. Rana A, Chisholm GD, Khan M, Sekharjit SS, Merrick MV, et al. (1993) Patterns of bone metastasis and their prognostic significance in patients with carcinoma of the prostate. Br J Urol 72: 933-936.

14. Ziessman HA, O'Malley J, Thrall JH (2006) The requisites Nuclear Medicine. Mosby. Skeletal Scintigraphy: 113-158.

15. Sasaki T, Onishi T, Hoshina A (2012) Cutoff value of time to prostatespecific antigen nadir is inversely correlated with disease progression in advanced prostate cancer. Endocr Relat Cancer 19: 725-730.

16. Kwak C, Jeong SJ, Park MS, Lee E, Lee SE (2002) Prognostic significance of the nadir prostate specific antigen level after hormone therapy for prostate cancer. J Urol 168: 995-1000.

17. Yigitbasi O, Ozturk U, Goktug HN, Gucuk A, Bakirtas H (2011) Prognostic factors in metastatic prostate cancer. Urol Oncol 29: 162-165.

18. Epstein JI, Allsbrook WC Jr, Amin MB, Egevad LL; ISUP Grading Committee (2005) The 2005 International Society of Urological Pathology (ISUP) Consensus Conference on Gleason Grading of Prostatic Carcinoma. Am J Surg Pathol 29: 1228-1242.

19. Laaksonen DE, Laukkanen JA, Niskanen L, Nyyssönen K, Rissanen TH, et al. (2004) Serum linoleic and total polyunsaturated fatty acids in relation to prostate and other cancers: a population-based cohort study. Int J Cancer 111: 444-450. 
Citation: Aydogan F, Kalender E, Rifaioglu MM, Sümbül AT, Yengil E (2014) The Effect of BMI and Visceral Fat Percentage on the Development of Bone Metastases in Prostate Cancer. J Nucl Med Radiat Ther 5: 193. doi:10.4172/2155-9619.1000193

Page 4 of 4

20. Calle EE, Rodriguez C, Walker-Thurmond K, Thun MJ (2003) Overweight, obesity, and mortality from cancer in a prospectively studied cohort of U.S. adults. N Engl J Med 348: 1625-1638.

21. Rodriguez C, Patel AV, Calle EE, Jacobs EJ, Chao A, et al. (2001) Body mass index, height, and prostate cancer mortality in two large cohorts of adult men in the United States. Cancer Epidemiol Biomarkers Prev 10: 345-353.

22. Veierød MB, Laake P, Thelle DS (1997) Dietary fat intake and risk of prostate cancer: a prospective study of 25,708 Norwegian men. Int J Cancer 73: 634-638.

23. Habel LA, Van Den Eeden SK, Friedman GD (2000) Body size, age at shaving initiation, and prostate cancer in a large, multiracial cohort. Prostate 43: 136-143.

24. Lee IM, Sesso HD, Paffenbarger RS Jr (2001) A prospective cohort study of physical activity and body size in relation to prostate cancer risk (United States). Cancer Causes Control 12: 187-193.

25. Jonsson F, Wolk A, Pedersen NL, Lichtenstein P, Terry P, et al. (2003) Obesity and hormone-dependent tumors: cohort and co-twin control studies based on the Swedish Twin Registry. Int J Cancer 106: 594-599.

26. Gallina A, Karakiewicz PI, Hutterer GC, Chun FK, Briganti A, et al. (2007) Obesity does not predispose to more aggressive prostate cancer either at biopsy or radical prostatectomy in European men. Int J Cancer 121: 791-795.
27. Giovannucci E, Rimm EB, Liu Y, Leitzmann M, Wu K, et al. (2003) Body mass index and risk of prostate cancer in U.S. health professionals. J Natl Cancer Inst 95: 1240-1244.

28. Porter MP, Stanford JL (2005) Obesity and the risk of prostate cancer. Prostate 62: 316-321.

29. Snowdon DA, Phillips RL, Choi W (1984) Diet, obesity, and risk of fatal prostate cancer. Am J Epidemiol 120: 244-250.

30. Gong Z, Neuhouser ML, Goodman PJ, Albanes D, Chi C, et al. (2006) Obesity, diabetes, and risk of prostate cancer: results from the prostate cancer prevention trial. Cancer Epidemiol Biomarkers Prev 15: 1977-1983.

31. MacInnis RJ, English DR (2006) Body size and composition and prostate cancer risk: systematic review and meta-regression analysis. Cancer Causes Control 17: 989-1003.

32. Hubbard JS, Rohrmann S, Landis PK, Metter EJ, Muller DC, et al. (2004) Association of prostate cancer risk with insulin, glucose, and anthropometry in the Baltimore longitudinal study of aging. Urology 63: 253-258.

33. Hsing AW, Sakoda LC, Chua S Jr (2007) Obesity, metabolic syndrome, and prostate cancer. Am J Clin Nutr 86: s843-857.

34. von Hafe P, Pina F, Pérez A, Tavares M, Barros H (2004) Visceral fat accumulation as a risk factor for prostate cancer. Obes Res 12: 1930-1935. 